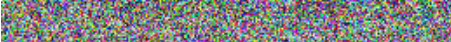

This information is current as of April 26, 2023.

\title{
Health Care Economics: A Study Guide for Neuroradiology Fellows,
} Part 2

S.L. Weiner, R. Tu, R. Javan and M.R. Taheri

AJNR Am J Neuroradiol 2018, 39 (1) 10-17

doi: https://doi.org/10.3174/ajnr.A5382

http://www.ajnr.org/content/39/1/10 


\title{
Health Care Economics: A Study Guide for Neuroradiology Fellows, Part 2
}

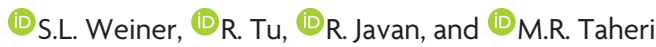

\begin{abstract}
SUMMARY: In this second article, we continue the review of current health care economics as it relates to radiologists, specifically framed by topics defined by the Accreditation Council for Graduate Medical Education in the evaluation of neuroradiology fellows. The discussion in this article is focused on topics pertaining to levels 4 and 5, which are the more advanced levels of competency defined by the Accreditation Council for Graduate Medical Education Neuroradiology Milestones on Health Care Economics and System Based Practice.
\end{abstract}

ABBREVIATIONS: ACGME = Accreditation Council for Graduate Medical Education; ACR = American College of Radiology; AMA = American Medical Association; APM = Advanced Alternative Payment Model; ASNR = American Society of Neuroradiology; CMS = Centers for Medicare and Medicaid Services; CPT = Current Procedural Terminology; GPCI = geographic practice cost index; MACRA = Medicare Access and Children's Health Insurance Program Reauthorization Act; MedPAC = Medicare Payment Advisory Commission; MIPS = Merit-Based Incentive Payment System; PE = practice expense; PLI = professional liability insurance; PQRS = Physician Quality Reporting System; PW = physician's work; QCDR = Qualified Clinical Data Registries; RUC = American Medical Association Specialty Society Relative Value Scale Update Committee; RVU = relative value unit

$\mathbf{F}$ ew resources are available in the medical literature for a comprehensive review of current health care economics as it relates to radiologists, specifically framed by topics defined by the Accreditation Council for Graduate Medical Education (ACGME) in the evaluation of neuroradiology fellows. Understanding and pragmatically applying the economic principles found in existing resources may be challenging for fellows, given the relatively fragmented dissemination of the principles in the literature. Therefore, we present a tailored discussion fashioned as a study guide for fellows to learn from and to gain competence in the ACGME neuroradiology milestones on health care economics. In addition, it is the authors' hope that this work might serve as a basic foundation for diagnostic radiology residents, other imaging subspecialty fellows, and practicing radiologists, facilitating their implementation in real-world radiology practice. This review article primarily relates to Medicare and its unique role in the physician reimbursement process. The role of private payers is beyond the

From the Neuroradiology Section, Department of Radiology, George Washington University Hospital, Washington, DC.

Paper previously presented, in part, as a digital exhibit at: Annual Meeting of the American Society of Neuroradiology, April 22-27, 2017; Long Beach, California.

Please address correspondence to M. Reza Taheri, MD, PhD, 900 23rd Street, NW, G2092, George Washington University, Washington, DC 20037; e-mail:

rtaheri@mfa.gwu.edu

- Indicates open access to non-subscribers at www.ajnr.org

http://dx.doi.org/10.3174/ajnr.A5382 scope of this effort and will not be explored to any meaningful degree. Finally, this work will be presented as a 2-part review article, with Part 1 covering ACGME milestones 1-3 and Part 2 covering milestones 4 and 5 .

\section{MATERIALS AND METHODS}

A search using the PubMed Medical Subject Heading terms "diagnostic imaging/economics" and "radiology/economics" performed in late 2016 resulted in a nonexhaustive compilation of approximately 50 review articles on the topic of current health care economics, nearly all of which were published within the past 5-6 years, many within the past $1-2$ years. From these, approximately 20 reference articles were used to synthesize a relatively comprehensive compendium of useful information on the topic, with the ACGME neuroradiology milestones on health care economics and systems-based practice serving as a framework.

\section{ACGME Neuroradiology Milestones on Health Care Economics and Systems-Based Practice: Redefining the Levels}

Please refer to Part 1 of this Review for the general background and explanation of the ACGME neuroradiology milestones.

The 5 levels for measuring a neuroradiology fellow's competence in health care economics are outlined in Table 1 of Part 1 of this review and are presented in order as major section headings (levels) within this article. 
Table 1: Physician payment calculation for a brain MR imaging without dye in the Washington, DC area

Payment Calculation

Total RVU $=(1.48 \times 1.048)+(4.95 \times 1.205)+(0.09 \times 1.271)$

Total RVU $=1.55+5.96+0.11=7.62$

Payment $=7.62 \times \$ 35.8887$

Total $=\$ 273.47$

\section{Level 4: Medicare Reimbursements and Bonus Payments for Radiology Studies}

Formula for Calculating a Dollar Value in a Physician Fee Schedule. Each Current Procedural Terminology (CPT) code has a corresponding relative value unit (RVU), which determines the physician's payment and the global payment. The physician payment formula for each CPT code contains 3 RVU components: 1 for physician's work (PW), 1 for practice Centers for Medicare and Medicaid Services (CMS) expense (PE), and 1 for professional liability insurance (PLI) expense. ${ }^{2,3}$ Average CMS costs (total physician reimbursements across all codes) broken down proportionately into PW, PE, and PLI have been previously estimated at $52 \%, 44 \%$, and $4 \%$, respectively. ${ }^{2}$ Each of these 3 RVU components is adjusted by a geographic practice cost index (GPCI), which accounts for variations in the cost of living, wages, malpractice premiums, and overhead costs in specific geographic locations. The GPCI is a weight and relativity methodology to neutralize the variation in PLI cost across regions so that in general, one area may gain RVUs at the cost of another. The data are reported by zip code; therefore, the GPCI may be different within a given state and even a given county. Most interesting, Puerto Rico and the Pacific territories follow CMS guidelines as well, and there is consideration for revision of GPCI methodology for these regions to increase their GPCI. Finally, as a reflection of the Protecting Access to Medicare Act legislation in 2014, the physicians in California will benefit from greater GPCI payments in aggregate. ${ }^{4}$

PW RVU represents the RVUs for the physician's time, skill, training, and intensity of work going into the production of a professional service. PE represents the RVUs of the physician's practice expenses going toward the service in question, including equipment, rent, supplies, and nonphysician staff costs. PLI represents the RVUs for the PLI premium or risk assigned to the service. Each of these 3 relative cost factors is adjusted for its own GPCI in the formula. In other words, there is $1 \mathrm{GPCI}$ for PW, 1 for PE, and 1 for PLI. Finally, the total RVUs are multiplied by a conversion factor to determine a total payment amount. The conversion factor, which is updated annually, is currently $\$ 35.8887$ for 2017 per the "Final Policy, Payment, and Quality Provisions in the Medicare Physician Fee Schedule for Calendar Year (CY) 2017" (https://www.cms.gov/Newsroom/MediaReleaseDatabase/ Fact-sheets/2016-Fact-sheets-items/2016-11-02.html) on the CMS. gov Web site.

Therefore, based on the discussion above, the physician payment formula is as follows:

Total Physician RVU $=\left(\mathrm{PW}\right.$ RVU $\left.\times \mathrm{GPCI}_{\mathrm{PW}}\right)+(\mathrm{PE} \mathrm{RVU} \times$ $\left.\mathrm{GPCI}_{\mathrm{PE}}\right)+\left(\mathrm{PLI} \mathrm{RVU} \times \mathrm{GPCI}_{\mathrm{PLI}}\right)$,

Payment $=$ Total RVU $\times$ CF.

A sample physician payment calculation using the payment formula above for a brain MR imaging without dye in the Washington, DC area is found in Table 1)..$^{5,6}$

Physician Quality Reporting System. In the early 2000s, a payfor-performance plan was developed that used a fee-for-service model, which provided incentives for quality and efficiency improvement, known as the Physician Quality Reporting System (PQRS). CMS first introduced the PQRS in 2007 as a metric to quantify performance per a value-based reimbursement model, and it was later incorporated into the Affordable Care Act in 2010. ${ }^{7}$ The PQRS was initiated as a voluntary program with bonus payments paid for reporting specified quality measures equaling up to $2 \%$ of a physician's Medicare reimbursement. Participatory incentives were $0.5 \%$ of all Medicare payments in 2014. Penalties for noncompliance were then instituted in 2015, ranging from $2 \%$ to $4 \%$ for groups opting not to participate, with incentive payments being phased out that same year. Compounding that issue, the number of quality measures required to avoid a penalty increased from 3 in 2014 to 9 in 2015. ${ }^{8,9}$

Examples of PQRS measures for neuroradiology include the following: radiology reports that include specific items for acute stroke imaging, including whether hemorrhage, mass, or acute infarction are present; specifying the diameter of the proximal internal carotid artery compared with the diameter of the distal internal carotid artery; and patients with cerebrovascular accident undergoing endovascular therapy who have a window to canalization time of $<2$ hours divided by all patients with cerebrovascular accident undergoing endovascular stroke treatment. Other examples of radiology-specific PQRS measures include the following: reporting fluoroscopy exposure time; comparison with prior imaging studies for all patients having bone scintigraphy; appropriate imaging follow-up of incidental abdominal lesions; imaging follow-up for incidental thyroid nodules; and a reminder system for women 40 years of age and older undergoing screening mammography, providing a target due date for the next mammogram. Another metric, which has a negative impact, reports the use of "probably benign" findings in screening mammography when findings of appropriate assessments are negative, benign, or incomplete. Finally, a metric exists for biopsy follow-up for new patients to ensure that the results of the biopsy have been reviewed and communicated to the patient and the referring physicians. ${ }^{7,10}$

There are, however, several problems with pay-for-performance plans such as the PQRS. ${ }^{7}$ First, they offer no good tools to evaluate performance. In addition, the metrics used to assess performance are not reflective of health outcomes. Moreover, the measurement criteria are applied without a control to establish that any improvement can be attributed to the pay-forperformance plan. Finally, this kind of scheme can negatively transition from value-based reimbursement to "metric-based medicine," inadvertently bypassing the physician-patient relationship and the patient's satisfaction, in our eagerness to add value and avoid penalties. Truly implementing such pay-forperformance plans without improving health outcomes is both irrelevant and dangerous. Collecting data on measures that improve health outcomes and linking those measures to reimbursement will be an important step toward value-based health care. 
Medicare Payment Advisory Commission. The Medicare Payment Advisory Commission (MedPAC) was established in 1997 by the Balanced Budget Amendment to serve as an advisory body to Congress in the areas of quality of care, access to care, and Medicare spending. ${ }^{11}$ MedPAC continues to convene publicly to discuss items of policy and codify its recommendations to Congress. During the committee meetings, commissioners examine the findings of staff research, proposals by policy experts, and observations from other stakeholders. Committee members and staff will also hear suggestions and recommendations on issues related to Medicare through frequent meetings with stakeholders in the program, including congressional committee staff and CMS, health care providers and researchers, and beneficiary proponents. The recommendations of the Commission are published twice per year, in March and June.

Within chapter 4 of the March 2016 report of MedPAC to Congress (http://www.medpac.gov/search-results/page/6?index Catalogue $=$ searchresultsindex \&searchQuery $=$ March $+2016+$ report\&wordsMode $=0$ ), the Commission expressed persistent concerns regarding the fee schedule and nature of fee-for-service payments, which result in the undervaluation of primary care and the overvaluation of specialist practitioners, a recurring theme in MedPAC reports for many years. First, the Commission expressed concern that the resource-based relative value scale, which forms the basis for physician fee schedules, included mispriced services that resulted in an income divergence between primary care physicians and specialists. Second, members stated that fee-for-service payments allowed certain specialties to more readily boost the quantity of services provided (resulting in increased Medicare reimbursements), while MedPAC argued that other specialists had a more limited ability to increase the quantity of services. Using data from the Medical Group Management Association Physician Compensation and Production Survey of 2014, (http://www. mgma.com/Libraries/Assets/Key-Findings-PhysComp_FINALwith-copyright.pdf), MedPAC found that average compensation was substantially higher for some specialties compared with others, with compensation for nonsurgical procedures and radiology being more than twice the average for that of the primary care physicians. MedPAC argued that these disparities persisted when reimbursement was examined on an hourly basis, accounting for variation in work hours per week. They also persisted when compensation was simulated as if all services the physicians provided were paid under the CMS fee schedule, suggesting that an important source of compensation disparity among primary care and specialist physicians was the fee schedule itself, not specialty-specific variation in payers.

MedPAC seeks to validate the RVUs of fee schedules to correct inaccuracies and curtail overcompensation for physicians at the higher end of the compensation scale. In addition, MedPAC has made recommendations for a per-beneficiary payment system for primary care, replacing the expiring Primary Care Incentive Payment Program, in an attempt to shift Medicare spending to primary care from procedural services. Per-beneficiary payments would be funded by reducing fees for all services within the fee schedule other than Primary Care Incentive Payment Programdefined primary care services, in a budget-neutral model, helping to rebalance the fee schedule toward greater payment equity between primary care and specialist services.

Imaging 3.0. Imaging 3.0 is a compilation of strategies and practical measures developed and put forth by the American College of Radiology (ACR) to help move radiology practices forward successfully, charting a course through the unique challenges and opportunities of our evolving health care system. It seeks to optimize the patient encounter, referring physician collaboration, value proposition, physician administration relations, financial management, and leadership in the professional, social, and political realms. The Medicare Access and Children's Health Insurance Program Reauthorization Act (MACRA) is one way in which physicians in general and radiologists in particular can take part in the financial management aspects of Imaging 3.0, and it will be discussed in more detail next.

MACRA. The Medicare Access and Children's Health Insurance Program Reauthorization Act of 2015 represents the new overarching vision of the US Department of Health and Human Services regarding health care in the United States, focusing on "better care, smarter spending, and healthier people."12 MACRA seeks to achieve these goals by changing how health care is delivered to bolster value and quality over quantity and through encouraging more efficient clinical decision-making. ${ }^{13}$ In April 2016, CMS released a detailed regulatory framework for implementing MACRA via the Quality Payment Program. The Quality Payment Program essentially requires that Medicare Part B payments be distributed via either advanced alternative payment models or the MeritBased Incentive Payment System (MIPS, Table 2). ${ }^{13,14}$

The MIPS is a modified fee-for-service payment model brought under the quality umbrella by consolidating current federal performance programs, such as the PQRS noted above, the value-based payment modifier, and the practical use of an approved electronic medical record system and merging them with the Clinical Practice Improvement Activities. Detailed feedback on this proposal has been proffered by the ACR, Society of Interventional Radiology, and American Society of Neuroradiology, to name a few. Because a large proportion of eligible clinicians, including radiologists, will initially fall into the MIPS domain under the proposed Quality Payment Program structure, the MIPS will be discussed first.

Eligible clinician payment adjustments will be determined by the following provisions set forth in the MIPS component of the Quality Payment Program, receiving a composite performance score that reflects a combined weighting across 4 categories: 1) quality (replacing PQRS), 2) patient care information advancement (reflecting use of technologies such as an electronic medical record), 3) Clinical Practice Improvement Activities, and 4) cost. ${ }^{14}$ Payment adjustment under MIPS will be based on an initial performance period starting in 2017, and MACRA will begin to impact physicians' Medicare Part B reimbursements in 2019. The initial weightings for 2019 for the 4 categories discussed above will be $50 \%$ for quality, $25 \%$ for Advancing Care Information, 15\% for Clinical Practice Improvement Activities, and 10\% for resource use. MIPS-eligible clinicians' Medicare Part B reimbursements are slated for 2019 for an upward or downward adjustment of $4 \%$, based on performance measured in 2017, given 


Definition
Payment adjustment components
Basic inclusion requirements
Benefits/penalties
Effective date (begins impacting
physicians' Medicare Part B
reimbursements)

Merit-Based Incentive Payment System

Quality (replaces PQRS)

Advancing care information required

(eg, use of EMR)

Implementing CPIAs is required

Measures of cost

Fail to meet the 3 requirements to be in an AAPM (see cell to the right)

Upward or downward adjustment of $4 \%$, based on performance measured in 2017

Percentage adjustment increases each year, reaching a maximum of $\pm 9 \%$ in 2022

Increase in fee schedule conversion factor used to calculate Medicare Part B payments of $0.25 \%$ per year 2019
Advanced Alternative Payment Model

Quality measures like MIPS

Otherwise, varies on the basis of APM model (eg, BPCl, Next Generation Accountable Care Organization Model, and so forth)

Use of approved EMR

Base reimbursement on quality measures like MIPS Required to bear "more than nominal" financial risk QPs not subject to budget-neutral payment/adjustment

Automatic $5 \%$ bonus payment based on aggregate Medicare Part $B$ payments during the first 6 years Beginning in 2026, 3-fold increase for QPs in their fee schedule conversion factor used to calculate Medicare Part B payment of $0.75 \%$ per year for QPs 2019

Note:-AAPM indicates Advanced Alternate Payment Model; BPCI, Bundled Payments for Care Improvement Initiative; EMR, electronic medical record; CPIA, Clinical Practice Improvement Activities; QP, Qualifying Participant.

the CMS proposed 2-year interval between performance measurement and payment adjustment. This percentage adjustment increases each year, reaching a maximum of $\pm 9 \%$ in 2022 , resulting in a potential huge payment differential of $18 \%$. Positive or negative adjustments under MIPS will be based on a composite performance score with budget neutrality across the entire physician fee schedule, resulting in a portion of poor performers' reimbursements being redistributed to high performers. ${ }^{14}$

MIPS performance measures for radiologists according to the ruling of the CMS mirror PQRS measures as noted above and include the following: fluoroscopy exposure time; improper use of "probably benign" classification in mammogram screening reports; comparison with prior imaging studies for all patients in whom bone scintigraphy is performed; measuring the degree of stenosis in carotid imaging reports; a reminder system for screening mammography; use of a standardized nomenclature for CT; keeping a running tally of potential high-dose radiation imaging studies, specifically CT and nuclear medicine cardiac studies; using a radiation dose index registry; access to prior CT images for patient follow-up and comparison; follow-up CT for incidental pulmonary nodules per recommended guidelines; imaging follow-up of incidental abdominal lesions; imaging follow-up of incidental thyroid nodules; and use of dose-minimizing techniques for adult CT. ${ }^{12}$

Regarding MIPS performance measures, it seems logical that appropriate provisions for special consideration under the MIPS path need to be in place for clinicians with infrequent face-to-face patient encounters, such as radiologists, by reweighing MIPS performance categories to account for the unique circumstances facing these providers. ${ }^{15}$ The CMS previously proposed granting special consideration to physicians with no more than 25 patientfacing encounters in a billing cycle. This proposed criterion would result in a large fraction of radiologists being evaluated on the basis of measures not reflective of their practice and beyond their direct control. The ACR, the American Society of Neuroradiology (ASNR), and the Society of Interventional Radiology have recom- mended that the language "nonpatient facing" not be used to describe MIPS-eligible clinicians and have recommended alternative criteria and thresholds for when clinicians could receive special consideration. Second, it was proposed that the definition of "patient-facing encounters" be related solely to codes applying to office and outpatient visits at the exclusion of all codes for surgical procedures, given that radiologists commonly perform a diverse range of interventions (surgical procedures) such as thoracenteses, paracenteses, and biopsies, without seeing the patient in consultation before or after the procedure or maintaining a separate clinic to provide associated patient management.

The Health and Human Services Secretary is required by MACRA legislation to use Qualified Clinical Data Registries (QCDR) to ensure compliance with MIPS. QCDR is a CMS-approved construct that allows the tracking of patients and disease via the collection of medical/clinical data, thereby fostering enhancement in the quality of care provided to patients. ${ }^{16}$ The National Radiology Data Registries of the American College of Radiology have successfully received QCDR status, along with many other specialty societies. QCDR allows members of these societies the option of using specialty-specific data to comply with MIPS in a system that complies with all 4 MIPS performance categories discussed above. Using QCDR, physicians are reporting data reflective of quality of service as selected by peers, which will result in more consistent feedback, likely in the form of benchmark reports issued by the specialty society registry. QCDR reporting is favored by MACRA for both the freedom it provides to specialties and the voluminous amount of data it generates for CMS. In addition, QCDR can be used in its current form as a means to comply with PQRS.

The Advanced Alternative Payment Model (AAPM or just APM) is, by definition, any new approach to reimbursement for medical care that incentivizes higher value and quality while being exempt from the MIPS reporting requirements. The legislation lays out 3 strict criteria that an advanced APM must fulfill for its participants to attain MIPS-exempt status and receive the full benefit of participating in an APM. ${ }^{13}$ These CMS-designated 
APMs must do the following: 1) require the use of approved electronic medical record technology, 2) base reimbursement on quality measures comparable/similar to those in the MIPS quality performance category, and 3) require the participating entity to bear "more than nominal" risk financially under the Centers for Medicare and Medicaid Innovation authority. In addition, any individual clinicians who receive a certain percentage of either their Medicare Part B payments or covered Medicare beneficiaries through an APM are deemed APM-qualifying participants. In 2019 , these percentages start at $25 \%$ of payments or $20 \%$ of patients and will increase in subsequent years. Participants who fulfill a lower percentage (20\% payments/10\% patients) are deemed a partial qualifying participant. Participants in an APM who do not meet the 3 requirements for being an APM are deemed MIPS-eligible clinicians.

MACRA provides greater overall benefits for full qualifying participants in an APM because they are exempt from MIPS participation altogether. ${ }^{12}$ For example, qualifying participants are not subject to the budget-neutral positive or negative payment adjustments to which MIPS-participating clinicians are subject. Instead, the APM entity earns an automatic 5\% bonus payment based on aggregate Medicare Part B payments during the first 6 years of the program implementation (2019-2024), regardless of the actual achievement on the APM performance measures or actual realized savings. This $5 \%$ bonus payment only partially offsets losses that an APM may incur, given the required substantial (more than nominal) financial risk, losses that have been defined by regulators to be up to $4 \%$ of total APM Part A and Part B expenditures over expected expenditures. Subsequently, beginning in 2026, qualifying participants will benefit from a 3-fold increase in the annual update to the conversion factor used to calculate Medicare Part B payments, amounting to $0.75 \%$ per year for qualifying participants, compared with an increase of only $0.25 \%$ per year for MIPS-participating clinicians. These differences are expected to encourage a growing number of clinicians to participate in APMs as opposed to MIPS.

\section{Level 5: Valuation/Revaluation of CPT Codes-ACR and American Medical Association Roles}

CPT Development Process. The process for the development of new and revised CPT codes begins with any individual qualified health professional seeing the need for a new code or updates to an existing code, such as a radiologist in the case of radiology-relevant codes. ${ }^{17}$ The qualified health professional then submits a coding request form to the American Medical Association (AMA), which then reviews the proposed changes. The AMA staff then submits a request to the AMA CPT Advisory Committee, who reviews the request and presents it to the AMA CPT Editorial Panel, which convenes 3 times per year. The CPT Panel reviews the request and either approves, postpones, or rejects the proposal to add or revise the code. Finally, if the code is approved for a category I, the CPT Panel refers the code addition or change to the American Medical Association Specialty Society Relative Value Scale Update Committee (RUC) for valuation.

CPT Editorial Panel and CPT Advisory Committee. The AMA CPT Editorial Panel provides CPT review with physician input and is the forum for the development of new and revised CPT codes and ironing out problems related to code set maintenance. ${ }^{18}$ It comprises representatives from physicians, nonphysician health care providers, payers, the American Hospital Association, CMS, and some of the major insurance companies. The panel convenes thrice yearly to evaluate all code change proposals that are brought before the panel.

The AMA CPT Advisory Committee is the group that grants medical societies the opportunity to provide input into the CPT editorial process. ${ }^{18}$ The committee is quite large and comprises representatives of all national medical specialty societies that have seats in the AMA House of Delegates. It also comprises organizations representing limited-license professionals and other allied health care practitioners, such as the Health Care Provider Advisory Committee. The responsibilities of the CPT advisors include serving as a resource to the CPT Editorial Panel, submitting codechange proposals, and evaluating proposals forwarded by other groups that relate to the scope of practice of their specialty, whether submitted by individuals, vendors, payers, or others. The $\mathrm{CPT}$ advisors also produce supporting clinical documentation for new procedures and services being considered for new codes. They also promote and educate their societal members on the benefits and practical utility of CPT. Similar to the RUC, these society advisors work in cooperation with a plethora of staff provided by their respective organizations.

American Medical Association/Specialty Society ResourceBased Relative Value Scale Update Committee. The American Medical Association/Specialty Society Resource-Based Relative Value Scale Update Committee, also known as the RUC, is an expert multispecialty consensus panel formed by 31 physicians from multiple medical specialties and societies, including radiology. The AMA Board of Trustees chooses the RUC chairperson and the AMA representative to the RUC. ${ }^{19}$ Specialty societies nominate individual members of the RUC who then must be approved by the AMA. The group, which first met in May 1991, is tasked with ongoing review of the accuracy and relevance of the resource-based relative value scale and determining the rank-order placement of newly introduced procedures into the system. ${ }^{2,11}$ The CMS accepts the recommendations from the RUC more than $90 \%$ of the time, and per CMS, those changes must be made in an environment of budget neutrality. Therefore, if the RUC makes a recommendation to increase the RVUs for a particular service, the RVUs of all other services must be proportionately decreased. This potentially inimical situation is tempered by the frequent need for cooperation between societies to advance codes together in a setting of shifting alliances. Voting members of the RUC are barred from advocating for code valuations presented by the societies they represent and must sit on the committee as impartial judges of valuation. Such checks and balances function to dampen any intersocietal conflict that might arise.

The RUC meets 3 times per year to hear recommendations from advisors from $>100$ medical specialty societies regarding their assessment of the relative value of procedures performed by its members. As noted above, radiology holds a seat on the committee, with other imaging-related societies in regular attendance including the ASNR, the Society of Interventional Radiology, and the Society of Nuclear Medicine. The ASNR, in particular, con- 
tinues to be currently represented at RUC committee meetings by RUC and CPT advisors. The representatives of these societies have forged a close working relationship across the years, despite occasional turnover in personnel.

Relativity Assessment Workgroup. A vital process explicit in the charter of the RUC was the review of the entire Resource-Based Relative Value Scale every 5 years. After the third such review in 2007, the CMS requested an ongoing review process via the "FiveYear Review Committee," which was subsequently renamed the "Relativity Assessment Workgroup." ${ }^{20}$ This workgroup was tasked with reviewing potentially misvalued codes based on several screening criteria, including CPT codes missing a verifiable data trail, codes demonstrating increasing use, change in the physician specialty reporting the code, or change in the site of service. Another screen used by the Relativity Assessment Workgroup is for "codes performed together," which is particularly relevant to radiology as mentioned in the code bundling section above. CPT codes, which are typically reported together on a single Medicare patient on the same day of service (eg, CT abdomen and CT pelvis) may have efficiencies that should be accounted for when determining overall relative value. As alluded to in the code bundling section above, this screen has expanded in significance and scope with time, initially triggered when codes were reported together $95 \%$ of the time and now triggered when reported together $50 \%$ of the time.

The effort of the Relativity Assessment Workgroup in devising its own screening processes for potentially misvalued codes has been well-received by CMS and has frequently targeted radiology, given the high technical component costs of advanced imaging. The various specialty societies are mandated to respond to the Relativity Assessment Workgroup or CMS screening inquiry and to devise a strategy for verifying appropriate valuation of both the technical and professional components of procedures. Once a code is identified in a screen as being potentially misvalued, specialty societies with a stake in establishing an RVU for the procedure are given the opportunity to submit evidence that the code values flagged by the screen are valued appropriately and should remain unaltered or that confounding factors would trigger downstream consequences if the code or code family is revalued. If the evidence fails to convince the Relativity Assessment Workgroup or CMS, there is either a revaluing of the service via survey or revision of the CPT nomenclature or code structure. More often, this is in the form of code bundling.

National Correct Coding Initiative. The National Correct Coding Initiative, which is the CMS counterpart to the Relativity Assessment Workgroup, also reviews codes for possible misuse. ${ }^{21}$ It was the National Correct Coding Initiative that identified 2 procedures, plain-film myelography and contrast-enhanced spinal CT as discussed above, requesting clarification from the AMA. The CMS was concerned that these concurrent procedures were potentially unnecessary and duplicative. After receiving detailed clarification from the ASNR that these are distinct procedures, the National Correct Coding Initiative put forth a recommendation that modifier 59 (Distinct Procedural Service) be appended to the CPT codes if the CT examination is performed following myelography on the same day on the same patient. Basically, modifier
59 identifies and clarifies procedures that might be mistaken as duplicative.

The RUC Process. The CPT code valuation process begins with the AMA RUC notifying member societies of the new/revised code after receiving the proposed changes from the CPT Panel. ${ }^{17}$ The sponsoring society (eg, the ASNR) and other interested societies conduct a survey regarding the new code and subsequently present the survey results and recommendations to the RUC. The RUC then either refers the recommended values to CMS for consideration or defers its decision to the next meeting, at which time they will resurvey or further examine the valuation after the ACR gathers additional information to support the code valuation.

Role of the ASNR. Largely due to the initial effort of neuroradiologist J. Arliss Pollock, MD, in the early 1990s, as well as the subsequent effort of other neuroradiologists, the ASNR has enjoyed an active role in the sphere of socioeconomic policy, including active participation in both the CPT and RUC processes across the years. ${ }^{11}$ Examples include the introduction of numerous new procedures including intraoperative MR imaging in 2003; kyphoplasty, intracranial angioplasty and stent placement, and carotid stent placement in 2005; and functional MR imaging in 2006. Moving these new technologies through CPT validation and RUC review required the collaboration of ASNR advisors and staff on multiple levels, including the synthesis of relevant research studies demonstrating effectiveness; gathering information to assess actual PW involved for each procedure to formulate reasonable RVU values; and finally, the presentation of the data and proposals to the CPT Panel and the RUC. ${ }^{11}$

The CMS Process. CMS then reviews the valuation recommendations from the RUC and releases a new CMS Medicare Physician Fee Schedule with proposed values. ${ }^{17}$ After these values are given a period of public comment, CMS publishes the Medicare Physician Fee Schedule with the final values for the subsequent calendar year. Last, there is a public comment period for the final values. See the Figure for an overview of the CPT code-development process.

Code Bundling Revisited: Unintended Consequences. Various medical societies are keenly aware of the downstream effects that CPT code revisions and code bundling have had on their respective communities, including radiologic societies. Code bundling results in both revisions in Medicare payments and renegotiation of private insurance contracts, and these revisions are not always favorable. ${ }^{20}$ For example, a new bundled service may fail to fully capture how a service is performed in the radiologic community, given the lack of procedural component parts reflected in the parent codes. The less detailed bundled code may lead to unintended inequities and confusion as to the reported cost of performing the procedure. One case in point was a multiyear project to bundle conscious sedation and anesthesia services into a base procedure, such as an interventional radiology procedure in which the physician performing the procedure typically performs the sedation. The CMS and RUC concluded that if such conscious sedation is typical, then it should not be billed separately and should be bundled into the base code being billed by the physician performing the procedure; this conclusion makes it extremely 


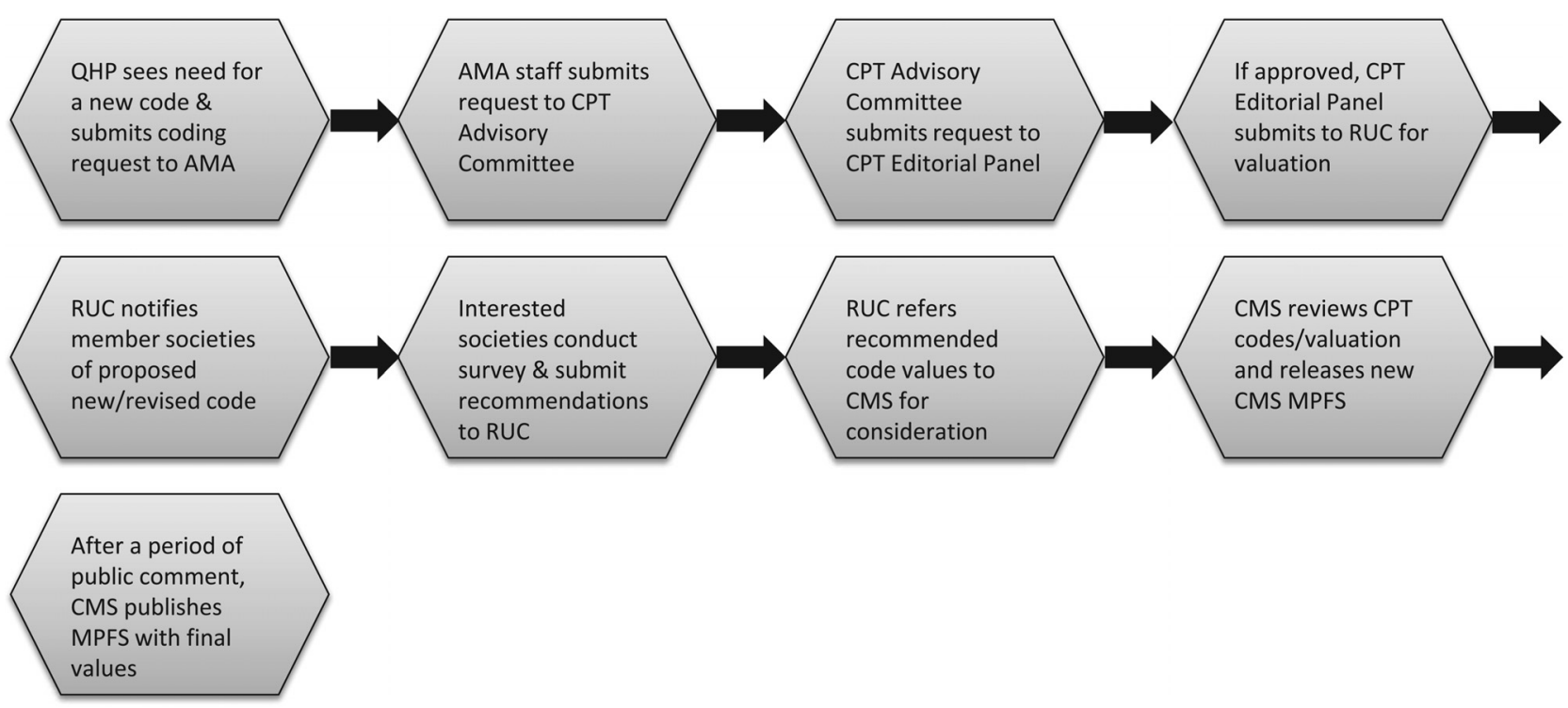

FIGURE. Overview of the CPT code development process. MPFS indicates Medicare Physician Fee Schedule; QHP, qualified healthcare professionals.

difficult to bill anesthesia services or conscious sedation in atypical circumstances or when an anesthesiologist is required. This led to confusion and payment inequities, which ultimately resulted in a new multiyear project of unbundling conscious sedation and anesthesia services from all previous base codes.

Ongoing Advocacy of the ACR on Behalf of Practicing Radiologists. The ACR has worked in support of the profession and patients through ongoing advocacy before Congress, federal agencies, state legislatures, and regulatory bodies. ${ }^{22,23}$ It has obtained coverage for lung cancer screening CT for patients and providers; repealed the Sustainable Growth Rate Formula of Medicare; reduced the Multiple Procedure Payment Reduction by $80 \%$, cutting it from $25 \%$ to $5 \%$; retained women's annual mammography screening coverage beginning at age 40; supported funding for advanced radiologic science by supporting Congress-passed legislation to increase the National Institutes of Health budget for the National Institute for Biomedical Imaging and Bioengineering; and worked to establish coverage for CT colonography, to name a few items.

\section{CONCLUSIONS}

Health care economics as it applies practically to radiologists is complex, with relatively fragmented dissemination in the current medical literature. Therefore, we have presented a tailored discussion in the form of a study guide for fellows to learn and gain competence with respect to the ACGME neuroradiology milestones on health care economics. While this article is targeted to neuroradiology fellows, it can be useful for others in the radiologic sciences and medicine as a whole. While not meant to be exhaustive, our aim is for this review article to serve as a basic foundation on which diagnostic radiology residents, imaging subspecialty fellows, practicing radiologists, and other medical and allied health care professionals can build, facilitating their implementation in real-world radiology/clinical practice.

Because health care economics is a constantly evolving entity, the following Web sites are provided as resources to follow some of the latest changes in the health care economics landscape.

CPT information: https://www.ama-assn.org/practicemanagement/cpt-current-procedural-terminology; https://www. ama-assn.org/practice-management/explore-recent-cpt-codechanges-actions.

MACRA MIPS information: https://www.acr.org/QualitySafety/Resources/MACRA-Resources.

Medicare information: https://www.cms.gov/Medicare/ Medicare.html.

RUC information: https://www.ama-assn.org/about-us/ruc.

\section{REFERENCES}

1. The Accreditation Council for Graduate Medical Education and The American Board of Radiology. The neuroradiology milestone project. Updated 2015. https://www.acgme.org/Portals/0/PDFs/Milestones/ NeuroradiologyMilestones.pdf. Accessed April 30, 2017

2. Baadh A, Peterkin Y, Wegener M, et al. The relative value unit: history, current use, and controversies. Curr Probl Diagn Radiol 2016; 45:128-32 CrossRef Medline

3. Petrey WB, Allen B Jr, Thorwarth WT Jr, et al. Radiology coding, reimbursement, and economics: a practical playbook for housestaff. J Am Coll Radiol 2009;6:643-48 CrossRef Medline

4. Centers for Medicare and Medicaid Services. Proposed policy, payment, and quality provisions changes to the Medicare physician fee schedule for calendar year (CY) 2017. Updated 2016. http://www. cms.gov/Newsroom/MediaReleaseDatabase/Fact-sheets/2016-Factsheets-items/2016-07-07-2.html. Accessed June 14, 2017

5. Centers for Medicare and Medicaid Services. PFS relative value files. Updated 2016. https://www.cms.gov/medicare/medicare-fee-forservice-payment/physicianfeesched/pfs-relative-value-files.html. Accessed May 16, 2017

6. Centers for Medicare and Medicaid Services. Physician fee schedule search. Updated 2016. https://www.cms.gov/apps/physician-feeschedule/search/search-criteria.aspx. Accessed May 16, 2017

7. Gupta D, Karst I, Mendelson EB. Value-based reimbursement: impact of curtailing physician autonomy in medical decision making. AJR Am J Roentgenol 2016;206:276-79 CrossRef Medline

8. Centers for Medicare and Medicaid Services. 2013 clinical quality measures. Updated 2015. https://www.cms.gov/Regulations-and- 
Guidance/Legislation/EHRIncentivePrograms/cqm_through_2013. html. Accessed May 16, 2017

9. Centers for Medicare and Medicaid Services. 2014 clinical quality measures. Updated 2015. https://www.cms.gov/Regulations-andGuidance/Legislation/EHRIncentivePrograms/2014_ClinicalQuality Measures.html. Accessed May 16, 2017

10. American College of Radiology. Qualified clinical data registry (QCDR) PQRS measures supported 2016. Updated 2016. https:// www.acr.org/ /media/ACR/Documents/PDF/QualitySafety/ NRDR/QCDR/ACR\%20QCDR\%20Measures\%20Supported\% 202016_PQRS.pdf. Accessed March 18, 2017

11. Donovan WD. The resource-based relative value scale and neuroradiology: ASNR's history at the RUC. Neuroimaging Clin N Am 2012;22:421-36 CrossRef Medline

12. Department of Health and Human Services. Center for Medicare \& Medicaid Services. Federal Register 81:28161-6. 42 CFR Parts 414 and 495. Medicare program; Merit-Based Incentive Payment System (MIPS) and Alternative Payment Model (APM) incentive under the physician fee schedule, and criteria for physician focused payment models. Updated 2016. https://www.gpo.gov/fdsys/pkg/FR-201605-09/pdf/2016-10032.pdf. Accessed March 7, 2017

13. Rosenkrantz AB, Nicola GN, Allen B Jr, et al. MACRA, alternative payment models, and the physician-focused payment model: implications for radiology. J Am Coll Radiol 2017;14:744-51 CrossRef Medline

14. Rosenkrantz AB, Nicola GN, Allen B, et al. MACRA, MIPS, and the new Medicare quality payment program: an update for radiologists. J Am Coll Radiol 2017;14:316-23 CrossRef Medline
15. Rosenkrantz AB, Hirsch JA, Allen B, et al. The proposed MACRA/ MIPS threshold for patient-facing encounters: what it means for radiologists. J Am Coll Radiol 2017;14:308 -15 CrossRef Medline

16. Hirsch JA, Leslie-Mazwi TM, Patel AB, et al. MACRA: background, opportunities and challenges for the neurointerventional specialist. J Neurointerv Surg 2016;8:868-74 CrossRef Medline

17. American College of Radiology. CPT code development process flowchart. https://www.acr.org/ /media/ACR/Documents/PDF/Economics/ CPT-Code-Development-Process-Flow81415.pdf. Accessed March 14, 2017

18. Hirsch JA, Leslie-Mazwi TM, Nicola GN, et al. Current procedural terminology; a primer. J Neurointerv Surg 2015;7:309-12 CrossRef Medline

19. The American Medical Association. Composition of the RVS update committee (RUC). https://www.ama-assn.org/about-us/compositionrvs-update-committee-ruc. Accessed June 14, 2017

20. Leslie Mazwi TM, Bello JA, Tu R, et al. Current procedural terminology: history, structure, and relationship to valuation for the neuroradiologist. AJNR Am J Neuroradiol 2016 Jul 14. [Epub ahead of print] CrossRef Medline

21. Chokshi FH, Tu RK, Nicola GN, et al. Myelography CPT coding updates: effects of $\mathbf{4}$ new codes and unintended consequences. AJNR Am J Neuroradiol 2016;37:997-99 CrossRef Medline

22. American College of Radiology. Recent ACR achievements on behalf of radiology. https://www.acr.org/Membership/Membership-Services/ Member-Benefits/What-Does. Accessed March 14, 2017

23. American College of Radiology. Advocacy. https://www.acr.org/ Advocacy. Accessed March 14, 2017 